\title{
PAKET WISATA PENDAKIAN GUNUNG BERBASIS WEB PADA PT. SEVEN MOUNTAIN ADVENTURE DENGAN MENGGUNAKAN PHP DAN MYSQL
}

\author{
Dedeh Supriyanti ${ }^{1}$ \\ Wahyu Hidayat ${ }^{2}$ \\ Rekha Apriyana ${ }^{3}$ \\ Dosen AMIK Raharja Informatika ${ }^{1}$, Magister Teknik Informatika STMIK Raharja ${ }^{2}$, \\ Mahasiswa STMIK Raharja ${ }^{3}$ \\ e-mail: $\underline{\text { dedeh@raharja.info }}{ }^{1}, \underline{\text { wahyu.hidayat@raharja.info }}^{2},{\underline{\text { rekha@ } \text { raharja.info }^{3}}}^{3}$
}

\begin{abstract}
ABSTRAKSI
Sistem Informasi Penjualan salah satu metode informasi yang memudahkan perusahaan dalam menganalisis dan mengambil keputusan dalam perencanaan strategi perusahaan dengan efektif dan efisien. Karna dapat menampilkan data- data yang ringkas dan sesuai kebutuhan. PT. Seven Mountain Adventure dirasa memerlukan adanya Sistem Informasi khususnya dalam bidang penjualan, karena PT. Seven Mountain Adventure Tangerang merupakan perusahaan distributor yang bergerak dalam bidang produk seperti perlengkapan adventure. Metodologi penelitian yang diterapkan dalam penulisan ini adalah dengan menganalisis sitem yang berjalan pada PT. Seven Mountain Adventure dan perancangan Sistem Informasi Penjualan yang dirancang dengan menggunakan Analisis SWOT, perancangan system yang berjalan dan yang diusulkan menggunakan UML (Unifed Modelling Language) dan pengujian program yang diusulkan menggunakan black box testing. Adapun perancangan aplikasinya menggunakan PHP (PHP Hypertext Prepocessor) dan pembuatan database dengan MySQL. Sistem Informasi Penjualan pada PT. Seven Mountain Adventure Tangerang ini membantu perusahaan untuk mendapatkan informasi yang cepat dan akurat, memusatkan perhatian pada hal- hal penting untuk mementukan masa depan perusahaan, menentukan realisasi penjualan yang up to date agar dapat mengetahui sejauh mana achievement yang diperoleh dari target penjualan, menentukan persaingan bisnis antar kolega, menentukan support program-program oleh principle, menentukan kebijakan- kebijakan perusahaan dalam mencapai visi dan misi perusahaan, serta mengoptimalkan kinerja perusahaan secara keseluruhan dalam penyusunan laporan informasi yang dibutuhkan oleh pihak eksekutif perusahaan.
\end{abstract}

Kata Kunci: Sistem Informasi Penjualan, Analisis.

\section{ABSTRACT}

Information system sales are one of the methods of the information makes it easy for companies in analyzing and taking decisions in planning corporate strategy with effective and efficient. Karna can display data that concisely and according to needs. PT. Seven Mountain Adventure reasonably requires the existence of a system of Information in particular in the areas of sales, because the PT. Seven Mountain Adventure Tangerang distributor company which supplies products such as adventure. Research methodology applied in writing this is to analyze the system that runs on PT. Seven Mountain Adventure and designing Sales information system designed by using SWOT analysis, designing system running and proposed using UML (Unifed Modelling Language) and testing the proposed program using black box testing. As for the design of the application using PHP (PHP Hypertext Prepocessor) and creation of databases with MySQL. Information system sales at PT Seven Mountain Adventure of Tangerang this helps companies to get information quickly and accurately, focus attention on things important to mementukan the future of the company, determine the realization of the sales are up to date in order to find out the extent to which the achievement of sales 
targets, determine the business competition between colleagues, determine support programs by principle, determining the company's policies in achieving the vision and mission of the company, as well as to optimize the performance of the company as a whole in the preparation of the report information required by corporate executives.

Keywords: Sales information system, analysis

\section{PENDAHULUAN}

Teknologi saat ini menjadi kebutuhan bagi suatu perusahaan untuk memenangkan sebuah persaingan dimana informasi digunakan sebagai penunjang keputusan, sehingga dibutuhkan penyampaian informasi yang cepat, tepat, dan akurat dalam mendapatkannya agar tidak kalah dalam persaingan. Informasi tersebut berisi situasi dan kondisi yang terjadi didalam maupun diluar perusahaan yang selanjutnya akan digunakan sebagai bahan evaluasi dasar untuk perencanaan strategis dan program kerja selanjutnya.

Seiring berkembang informasi khusus untuk para manajer guna pengambilan keputusan dan untuk mengetahui kondisi kinerja perusahaan, maka berkembanglah sebuah sistem informasi yang disebut Sistem Informasi Penjualan. Dengan sistem informasi penjualan sistem dapat ditampilkan bentuk ringkas dan tampilan data sesuai kebutuhan sehingga mempermudah seorang manajer dalam pengontrolan setiap saat.

\section{RUMUSAN MASALAH}

perusahaan yang terletak di kota tangerang ini menjual produk adventure dimana pemilik perusahan tersebut kesulitan untuk menganalisa data penjualan secara keseluruhan karena laporan yang ada masih memakai sistem yang manual yaitu dengan sistem Microsoft Office Excel.

\section{LANDASAN TEORI}

\section{Pengertian Sistem}

Kumpulan dari beberapa bagian yang memiliki keterkaitan dan saling bekerja sama serta membentuk suatu kesatuan untuk mencapai tujuan dari sistem tersebut.

\section{Pengertian Informasi}

suatu data atau objek yang diperoses terlebih dahulu sedemikian rupa sehingga dapat tersusun dengan terklasifikasi dengan baik sehingga memiliki arti bagi penerimanya, yang selanjutnya menjadi pengetahuan bagi penerima tentang suatu hal tertentu yang membantu pengambilan keputusan secara tepat".

\section{Pengertian Data}

bahan mentah yang perlu diolah sehingga menghasilkan informasi yang menunjukan fakta.

\section{Pengertian Analisis Sistem}

suatu proses untuk memahami sistem yang ada, dengan menganalisa jabatan dan uraian tugas (busisness users),proses bisnis (business prosess), ketentuan atau aturan (business rule), masalah dan mencari solusinya (business problem and solution), business tolls, danrencana-rencana perusahaan (business plans).

\section{Pengertian Rumah}

Bangunan gedung yang berfungsi sebagai tempat tinggal yang layak huni, Sarana pembinaan keluarga, cerminan harkat dan martabat penghuninya, serta aset bagi pemiliknya.

\section{Diagram Unified Modeling Language (UML)}

pemodelan desain program berorientasi objek yang digunakan untuk visualisasi, spesifikasi, pembangunan dan pendekomentasian artifak dari sistem perangkat lunak. 


\section{Definisi Adobe Dreamweaver}

aplikasi desain dan pengembangan webyang menyediakan editor WYSIWYG (What You See Is What You Get) visual (lebih dikenal sebagai design view) dan code editor dengan fitur standar seperti syntak highlighting, code completion dan code collapsing".

Definisi PHP (PHP Hypertext Preprocessor)

bahasa pemrograman yang digunakan secara luas untuk penanganan pembuatan dan pengembangan sebuah situs web dan bisa digunakan bersamaan dengan HTML.

\section{Definisi Database}

kumpulan data yang saling berkaitan, berhubungan yang disimpan secara bersama-sama sedemikian rupa tanpa pengulangan yang tidak perlu untuk memenuhi berbagai kebutuhan.

\section{Definisi MySQL}

salah satu database management system (DBMS) dari sekian banyak DBMS seperti Oracle, MS SQL, Postagre dan lainnya.

\section{Definisi XAMPP}

sebuah software web server yang didalamnya sudah tersedian database server MYSQL dan dapat mendukung pemrograman PHP.

\section{Use Case Diagram yang diusulkan}
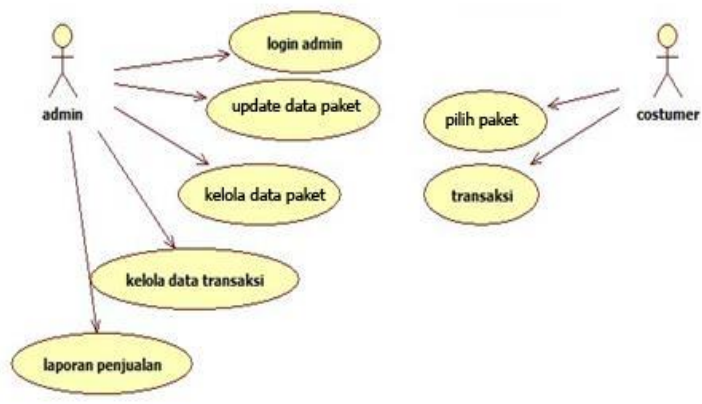

Gambar 1. Use Case Diagram Sistem Yang Diusulkan

\section{Activity Diagram yang Diusulkan}

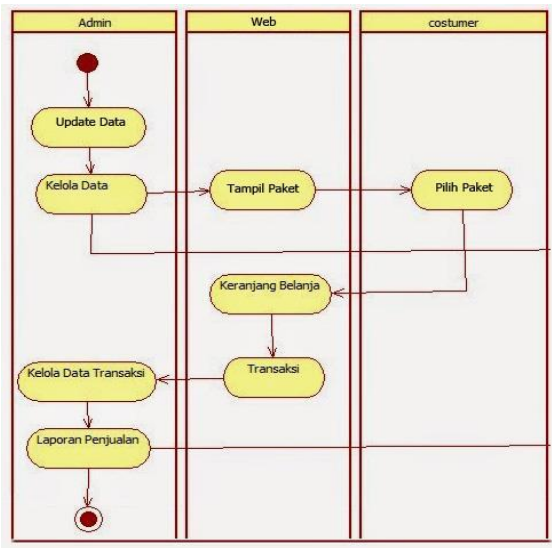

Gambar 2. Activity diagram Sistem Yang Di Usulkan 
Class Diagram Yang Diusulkan

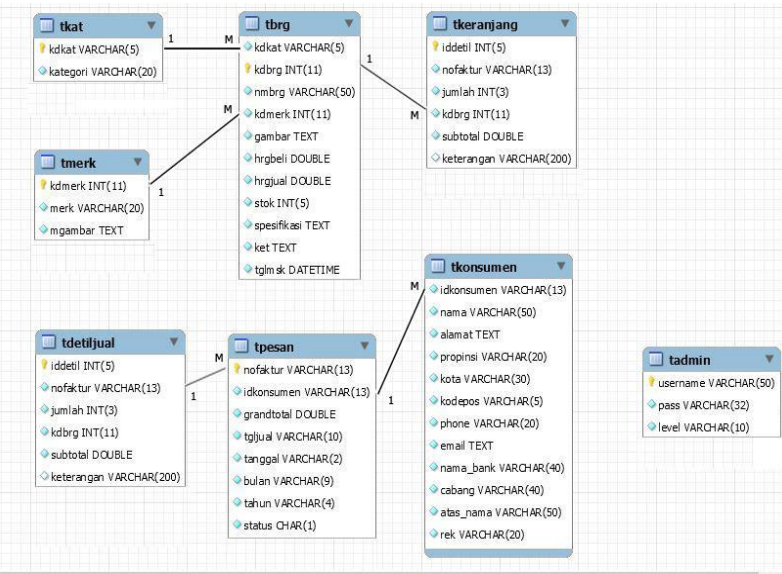

Gambar 3. Class Diagram Yang Diusulkan

Sequence diagram yang diusulkan

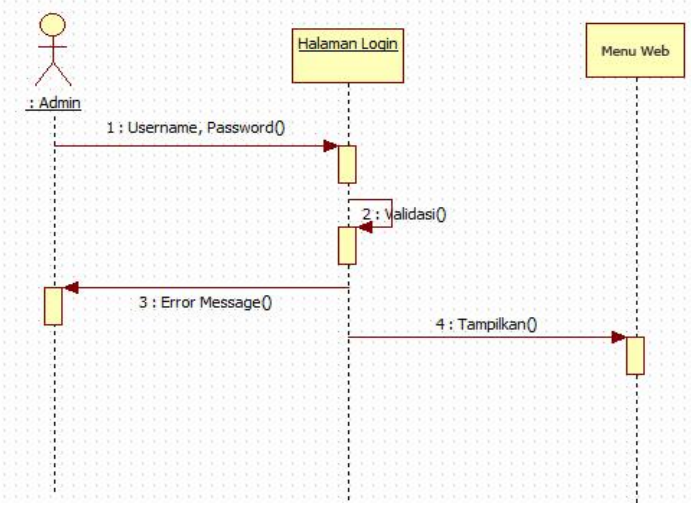

Gambar 4. Sequence Diagram yang diusulkan

\section{Rancangan Program}

a. Tampilan Halaman Home

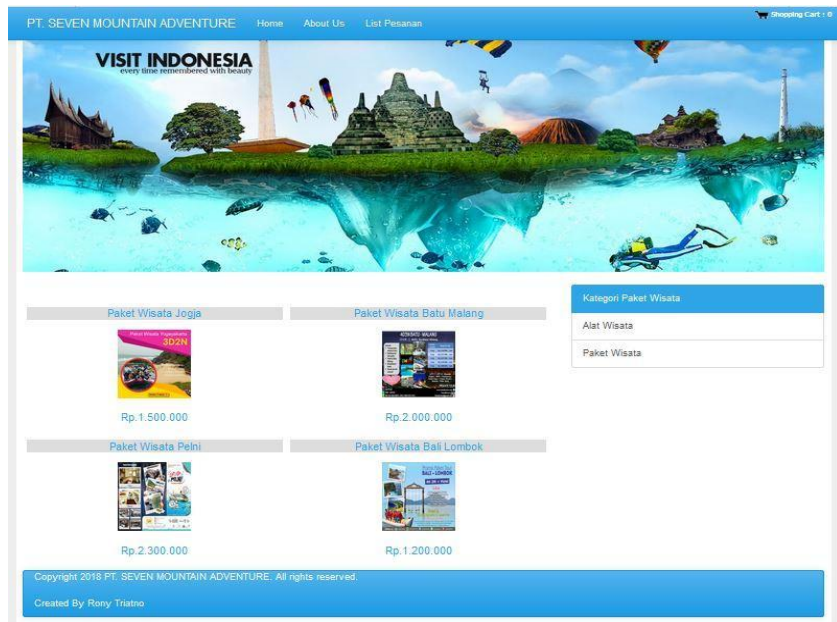

Gambar 5. Tampilan Halaman Home 
b. Tampilan Order

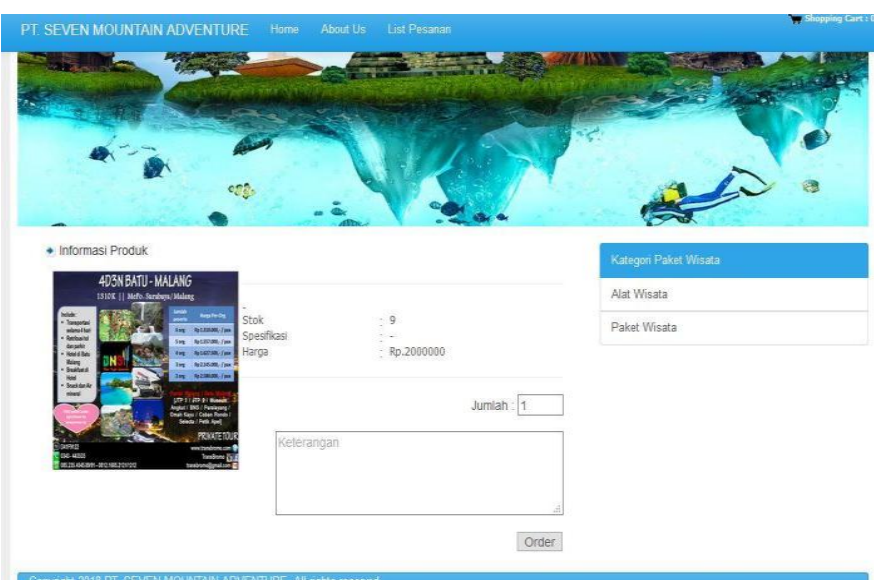

Gambar 6. Tampilan Order

c. Tampilan List Order

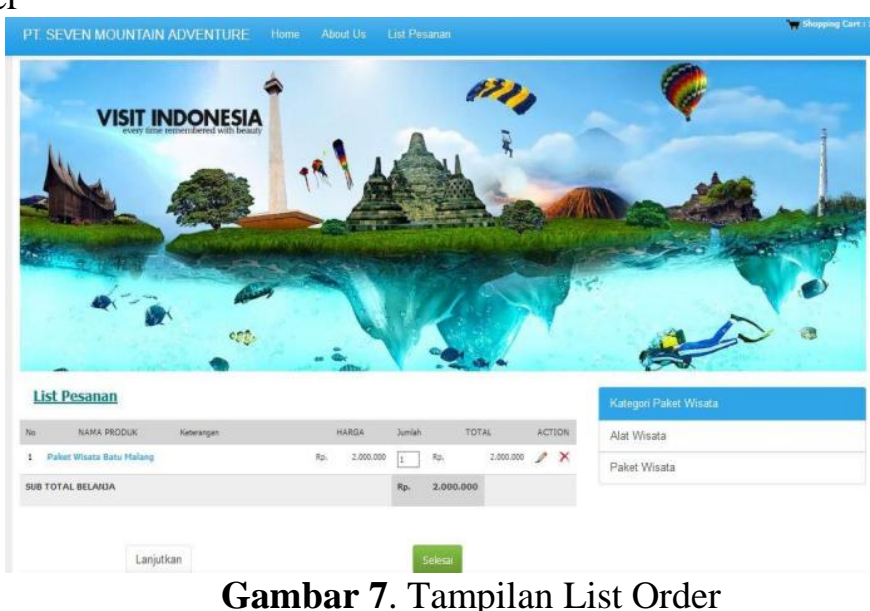

d. Tampilan Form Customer

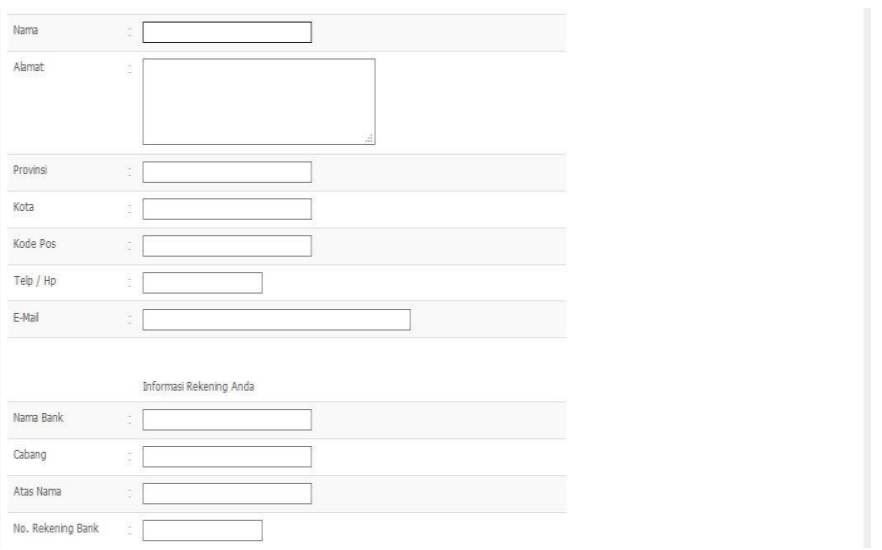

Gambar 8. Tampilan Form Customer 
e. Tampilan Login

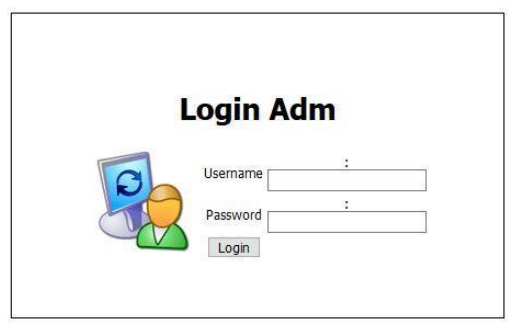

Gambar 9. Tampilan Login

f. Tampilan Admin Kelola

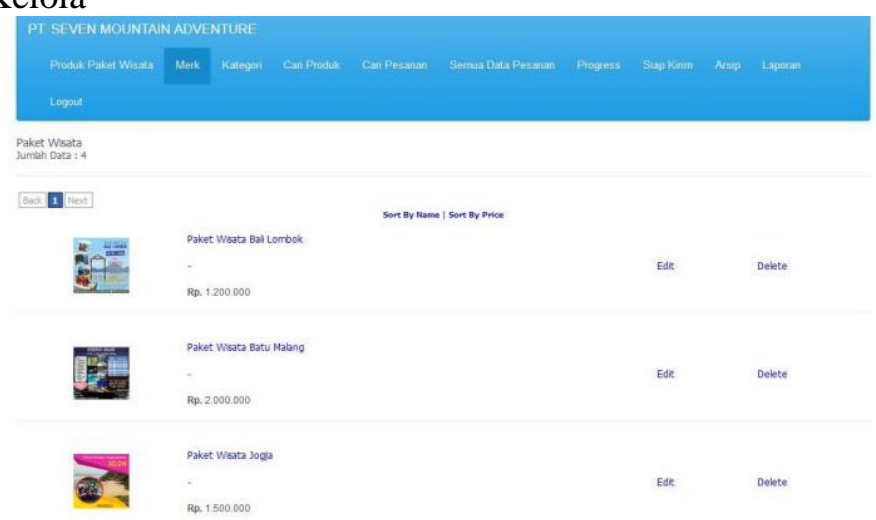

Gambar 10. Tampilan Admin Kelola

\section{LITERATURE REVIEW}

1. Menurut Priyo Sutopo, Dedi Cahyadi, Dan Zainal Arifin (Universitas Mulawarman, 2016) Penelitian yang berjudul "Sistem Informasi Penjualan Penjualan Kendaraan Bermotor Roda 2 Di Kalimantan Timur Berbasis Web" Penelitian tersebut membahas tentang Pesatnya penjualan kendaraan bermotor roda 2 di Kalimantan timur sangat cepat, hal tersebut menimbulkan masalah pedataan kendaraan tersebut di masing- masing wilayah di Kalimantan timur, dalam hal ini penjualanmengalami kesulitan dalam melihat penyajian data penjualan kendaraan bermotor atau grafik penjualan kendaraan, data yang di berikan untuk penjualan hanyalah laporan manual dan mungkin sangat sulit dipahami, sehingga tidak efektif dan efisien, sehingga dibutuhkan sebuah aplikasi untuk membantu penjualan dalam melihat penyajian data penjualan kendaraan bermotor dan grafik penjualan kendaraan. Aplikasi yang dapat memenuhi kebutuhan tersebut adalah sistem informasi penjualan sebaran kendaraan bermotor roda 2, Aplikasi yang mengegola sebaran penjualan kendaraan bermotor roda 2, Aplikasi ini memberikan kemudahan untuk para penjualan, karena aplikasi ini berbasis web jadi dapat dilihat di mana pun, dan data yang di berikan selalu terbaru, sehingga mempermudah penjualan mengambil keputusan untuk penjualan kendaraan bermotor.

2. Menurut I Ketut Suharsana ( STMIK STIKOM, 2015) Penelitian yang berjudul "Perancangan Sistem Informasi Penjualan Perkara Pada Pengadilan Negeri Wilayah Provinsi Bali" Penelitian ini membahas tentang Pengadilan Negeri atau Pengadilan Umum Tingkat Pertama merupakan lembaga yang menangani perkara baik perdata maupun pidana pada tingkat pertama. Jenis Perkara yang ditangani di pengadilan ini adalah perkara pidana dan perdata. Pengadilan Tinggi mendapatkan semua informasi perkara yang ditangani dari masing-masing Pengadilan Negeri. Informasi jenis perkara beserta jumlah dan periode akan dimudahkan apabila 
disajikan dalam bentuk grafik ataupun chart. Hal ini akan memudahkan penjualan yaitu Ketua Pengadilan Negeri dan Pengadilan Tinggi untuk melihat informasi mengenai jumlah perkara berdasarkan jenis dan tahunnya. Dengan adanya sistem ini, pihak ekskutif yang dalam ini Ketua Pengadilan Tinggi dapat melihat summary perkara dari masing-masing Pengadilan Negeri serta dapat melihat kecenderungan meningkat atau menurunnya suatu jenis perkara di suatu daerah sehingga dapat dilakukan bimbingan teknis (bimtek) bagi aparatur untuk meningkatkan pelayanan ataupun sosialisasi kepada masyarakat mengenai kesadaran hukum. Metode penelitian yang digunakan dalam penelitian ini adalah pendefinisian masalah, pengumpulan data, analisis sistem, perancangan sistem dan penarikan kesimpulan. Hasil dari penelitian ini berupa rancangan DFD, ERD dan struktur tabel.

3. Menurut Fauzan Aziz, Leon Andretti Dan Novri Hadinata (Uiversitas Muhammadiyah Palembang, 2015) Penelitian yang berjudul " Sistem Informasi Penjualan Berbasis Web Pada

Fakultas Pertanian Universitas Muhamamadiyah Palembang" Penelitian ini membahas tentang Teknologi informasi (TI) mampu memenuhi salah satu kebutuhan utama sebuah organisasi, seperti bagaimana penjualan mengetahui dan mengelola kinerja organisasi yang dipimpinnya, termasuk sumber daya manusia (SDM). Fakultas Pertanian Universitas Muhammadiyah Palembang (UMP) telah memiliki sistem informasi personalia yang digunakan untuk mengelola data SDM baik karyawan maupun dosen. Namun, sistem informasi hanya untuk mendukung kegiatan operasional saja. Oleh karena itu perlu dibangun sistem informasi penjualan (SIE). Dengan menggunakan SIE, dekan dapat dengan mudah mengakses visualisasi data ringkasan, yaitu munculnya informasi dalam bentuk grafik sehingga memudahkan pihak penjualan untuk membuat keputusan.

4. Menurut Rinaldy Virgiawan Soepaat, Tacbir Hendro P, Dan Faiza Renaldi (Prosiding SNATIF, 2017) Penelitian yang berjudul "Sistem Informasi Penjualan Di PT Bank Mega Bandung" Penelitian ini membahas tentang Bank Mega merupakan perusahaan Indonesia yang berbentuk perseroan terbatas dan bergerak di bidang jasa keuangan perbankan. Banyaknya cabang yang dimiliki Bank Mega membuat pengolahan datanya pun banyak seperti nasabah hingga pengguna kartu kredit. Perkembangan penggunaan kartu kredit terjadi dengan cepat karena ada banyak kemudahan yang diperoleh dari penggunaan kartu kredit. Dengan banyaknya masyrakat yang menggunakan kartu kredit pihak Bank MEGA Bandung mengalami masalah dalam mengetahui jumlah pengguna kartu kredit ditiap wilayahnya. Dan juga mengetahui seberapa banyak pengguna yang membuat kartu kreditnya di bank MEGA sendiri agar pimpinan dapat memberi bonus kepada pengguna kartu kredit.. Maka dari itu PT Bank Mega memerlukan sebuah sistem informasi penjualan yang dapat menunjukkan grafik skala peningkatan jumlah pengguna kartu kredit di berbagai kondisi. Penelitian ini telah menghasilkan sistem informasi penjualan yang dapat memberikan informasi jumlah pengguna kartu kredit berdasarkan wilayah, jenis kartu kredit hingga pekerjaan serta dapat menampilkan grafik dari kombinasi data seperti jumlah pengguna kartu kredit berdasarkan pekerjaan dan berdasarkan jenis kartu kredit per tahun sampai per bulan. Berdasarkan hasil pengujian terhadap sistem informasi penjualan di PT Bank Mega Bandung diperoleh tingkat keberhasilan sebesar $88,89 \%$, dimana 24 informasi dapat disajikan dan 3 informasi tidak dapat disajikan.

5. Menurut Fuja Noviansah, Leon Andretti Abdillah, Rusmin Syafari (Universitas Bina Darma, 2014) Penelitian yang berjudul "Sistem Informasi Penjualan Bagian Produksi Pada PT Perkebunan Nusantara VII (Persero) Distrik Banyuasin". Penelitian ini membahas tentang PT. Perkebunan Nusantara VII (Persero) Distrik Banyuasin adalah Badan Usaha Milik Negara (BUMN) yang bergerak pada bidang perkebunan di wilayah Sumaterabagian selatan. Dalam menjalankan aktivitas produksi nya sangatlah dibutuhkan suatu strategi produksi yang baik dan tepat agar dapat bersaing dengan perusahaan sejenis lainnya. PT. Perkebunan Nusantara VII (Persero) Distrik Banyuasin saat ini memiliki sejumlah aplikasi sistem informasi, termasuk salah satunya adalah sistem informasi yang digunakan dalam merekapitulasi data hasil produksi. Sistem informasi tersebut lebih menunjang untuk mengetahui kinerja hasil produksi sehingga belum menyajikan informasi atau laporan khusus bagi para penjualan. Kendala yang timbul dalam penyajian informasi atau laporan khusus bagi para penjualan pada PT Perkebunan Nusantara VII 
(Persero) Distrik Banyuasin tersebut mendorong penulis untuk membangun sistem informasi penjualan bagian produksi dengan hasil output dari sistem informasi tersebut berupa chart atau diagram laporan hasil produksi. Metode pengembangan sistem yang digunakan Web Engineering meliputi formulasi, perencanaan, analisis, rekayasa web, implementasi, evaluasi.

6. Menurut Luthfi Izhariman, Eko Darwiyanto, Dan Shita Yulia Puspitasari (e-Proceeding of Engineering, 2017) Penelitian yang berjudul "Perancangan Executive Information System Rumah Sakit Untuk Evaluasi Kinerja Pelayanan Di RSUP Mohammad Hosein Palembang" Penelitian ini membahas tentang RSUP Mohammad Hoesin merupakan rumah sakit rujukan utama di Provinsi Sumatera Selatan. Dikarenakan pembuatan laporan manajemen rumah sakit masih menggunakan cara manual, pihak manajemen rumah sakit mengalami kesulitan untuk mendapatkan informasi berupa indikator pelayanan medis yang dapat mengukur kinerja pelayanan rumah sakit. Oleh karena itu pada penelitian ini dilakukan perancangan Executive Information System (EIS) yang dapat mendukung proses pengolahan data rekam medik pasien hingga menampilkan informasi indikator pelayanan medis. Perancangan sistem ini membutuhkan data warehouse melalui proses ETL (extract, transform, load) pada data operasional rumah sakit dan menampilkan hasil analisis data dengan teknik OLAP (Online Analytical Processing).

7. Menurut Ida Bagus Ketut Surya Arnawa Dan I Ketut Dedy Suryawan (STIMIK STIKOM BALI, 2015) Penelitian yang berjudul "Perancangan Sistem Informasi Penjualan Bagian Akademik STIMIK STIKOM Bali Berbasis Web" penelitian ini membahas tentang dihasillkan sebuah rancangan sistem informasi penjualan bagian akademik pada STIMIK STIKOM bali berbasis web yang dapat memudahkan tim pengembang sistem dalam mengembangkan sistem informasi penjualan dan perancagan sistem ini akan digunakan oleh penjualan, dan Admin. Admin dapat maintenance semua data yang berkaitan dengan sistem informasi penjualan ini. Penjualan dapat melihat hasil data yang telah diolah oleh sistem dalam bentuk laporan".

8. Menurut Sri Widiyastuti, Leon Andretti Abdillah, Kurniawan (Fakultas Ilmu Komputer, 2014) Penelitian yang berjudul "Sistem Informasi Penjualan Bagian Kepegawaian Pada PT. Pelinda II (PERSERO) Palembang". Penelitian ini membahas tentang PT.Pelabuhan Indonesia II (Persero) adalah Badan Usaha Milik Negara (BUMN) yang bergerak pada bidang jasa pelabuhan yang berlokasi di Palembang. Dalam menjalankan aktivitas kinerja kepegawaiannya BUMN tersebut membutuhkan suatu strategi yang tepat agar dapat memenangkan persaingan. PT. Pelabuhan Indonesia II (Persero) saat ini sarana penyampaian informasi bidang kepegawaian tersebut kepada pihak penjualan masih berupa laporan yang disampaikan langsung oleh badann yang menangani bidang kepegawaian, sehingga data tersebut belum terintegrasi dengan data yang lain. Kendala yang timbul dalam penyajian informasi atau laporan khusus bagi para penjualan pada PT. Pelabuhan Indonesia II (Persero) tersebut mendorong penulis untuk membangun sistem informasi penjualan dengan hasil output dari sistem informasi tersebut berupa chart atau diagram kepegawaian. Metode pengembangan sistem yang digunakan yaitu EIS lifecycle yang terdiri dari justikasi, perencanaan, bisnis analisis, desain, kontruksi, dan deployment dan rilis.

\section{KESIMPULAN}

Sistem informasi penjualan produk yang berjalan pada PT. Seven Mountain Adventure masih menggunakan Ms. Excel dimulai dari penerimaan produk dari supplier, sistem yang berjalan sudah baik namun menimbulkan keterlambatan dalam proses pengolahan data, menyebabkan informasi yang dihasilkan tidak akurat. Sehingga untuk saat ini sistem yang berjalan masih belum memenuhi kebutuhan user. Untuk meminimalisir human errordiperlukan rancangan sistem dimana admin dan user bertugas menginput seluruh data penjualan. Dengan sistem yang terintegrasi, maka akan meminamalisir kesalahan penginputan datapenjualan produk. Agar dapat menjaga keakuratan data diperlukan rancangan sistem informasi eksekutif berbasis web, yang sangat memudahkan pihak eksekutif untuk mengecek hasil penjualan produk. Sehingga keakuratan data dapat terjamin dan tidak mudah di salah gunakan oleh pihak lain yang tidak berkepentingan. 


\section{DAFTAR PUSTAKA}

Aziz, Fauzan. Abdillah. Leon, Hadinati. Novi.2015.’'Sistem Informasi Eksekutif Berbasisi Web Pada Fakultas Pertanian Universitas Muhammadiyah Palembang"palembang:Jurnal Student Colloquium Sistem Informasi \& Teknik Informatika.

Arnawa,Surya.Ketut.Bagus.Ida, dan I. ketut. Dedy. Suryawan.2015."Perancangan Sistem Informasi Eksekutif Bagian Akademik STMIK STIKOM Bali Berbasis WEB"Bali:Jurnal Konferensi Nasional Sistem \& Informatika.9-10 Oktober 2015.

Bactiar, Dede. Atikah.2015. "Sistem Informasi Dashboard Kependudukan Di Kelurahan Manis Jaya Kota Tangerang”.STMIK Bina Saran Global.Jurnal Sisfotek Global.Vol.5 No.1 Maret 2015.ISSN:2088-1762.

Deviachrista.2013. ”Dasar Literature Riview'.Jakarta: Selemba Empat. Fitrianingsih, Fifit.

2014. Analisa Sistem Informasi Penggajian Karyawan Pada PT Jalur Sejuk". Tangerang: STMIK Raharja.

Hery.2016."Manajemen Bisnis Terintegrasi (Indonesia Edition)". Jakarta:Gramedia Widiasarana Indonesia (GRASINDO).ISBN:9786023755875.

Indrajani.2015. 'Database Design".Jakarta:PT Elex Media Komputindo.

Imtihan, Khairul.2015."Perancangan Strategi Informasi Pendidikan Pada Sekolah Tinggi Manajemen Informatika Dan Komputer (STMIK) Lombok".Lombok:Jurnal Bianglala Informatika.Vol.3 No.2 September 2015.

Izhariman, Luthfi. Eko Darwiyanto, S.T., M.T. Shinta Yulia Puspitasari, S.T., M.T.2017." Perancangan Executive Information System Rumah Sakit Untuk Evaluasi Kinerja Pelayanan Di Rsup Mohammad Hoesin Palembang,Palembang: E-Proceeding Of Engineering : Vol.4, No.3

Desember 2017. ISSN: 2355-9365.

Irwansyah, Edi. Jurike V, Moniaga.2014."Pengantar Teknologi Informasi".Jogyakarta:Deepublish.

Komputer, Wahana.2013."Mobile Web Development With Adobe Dreamweavercs6". Yogyakarta:Andi Offset.

Kurniawan, Sanja. Iriani. Siska. 2015. "Perancangan Sistem Informasi Penjualan Helm Pada Toko Helm Swaka Pacitan". Indonesian Journal On Networking And Security. Vol. 4 No. 3 2015. ISSN: 2302-5700.

Komara, Putrid. Intan. Tacbir, Hendro P. Faiza, Rinaldi.2017. "Sistem Informasi Eksekutif
$P T$.
PLN
(PERSERO)
Sumedang
Rayon

Tanjungsari”.Cimahi:UniversitasMuriaKudus.JurnalSNATIF,ISBN:978602-1180-50-1.

Murad, Dina. Fitria. Kusniawati. Nia, Asyanto. Agus.2013.”Aplikasi Intelligence Webside Untuk Penunjang Laporan PAUD Pada Himpaudi Kota Tangerang”.Tangerang:Pergiruan Tinggi Raharja.Jurnal CCIT .Vol.7 No.1 September 2013.ISNN: 1978- 8282.

Mishra, Atoll.2014."Critical Comporison Of PHP And ASP. Net For Web Development". Internasional Journal Of Scientific \& Technology Research. Vol 3 Issue 7 Juli 2014. ISSN: 2277-8616.

Maulani, Giandari. Rahardja, Untung. Adila Latifa, Tri.2016.”Video Sebagai E. Portofolio Mahasiswa Untuk Meningkatkan Keterampilan Mahasiswa".Tangerang:STMIK Raharja.Jurnal CCIT. Vol.9. 2 Januari 2016.ISSN:1978-8282.

Nurwidyantoro,Arif. Burhanudin. Hakim, Eko. Priyo. Utomo.2013."Perancangan Sistem Informasi Eksekutif (Studi Kasus Di UGM)".'Yogyakarta: Seminar Nasional Aplikasi Teknologi Informasi (Snati) 15 Juni 2013. Issn: 1907-5022. 